\title{
José Carlos Mariátegui, crítico de arte
}

\author{
ALFONSO CASTRILLON-VIZCARRA
}

\section{La producción intelectual}

Mariátegui aparece en la escena de la crítica de arte el año 14, enfrentando nada menos que a Teófilo Castillo a quien recomienda dedicarse solamente a la pintura, ya que "un pintor 'cabeceado" con literato no será, seguramente, buen pintor ni buen literato." Esta acre frase, que resentiría profundamente al pintor Castillo, venía a romper, de manera brusca quizá, la idea inveterada entre nosotros de que para opinar sobre pintura se tenía que ser pintor. Mariátegui no fue un especialista en arte, sino un pensador, un ideólogo: su interés no radicó en las técnicas o la historia del arte, sino en las ideas que están detrás de las imágenes. Mariátegui inaugura pues, entre nosotros, la crítica ideológica que, durante muchos años, no ha tenido seguidores.

¿Cómo se va delineando la personalidad de Mariátegui? Tradicionalmente se ha dividido en dos su vida intelectual, siguiendo es cierto, la clara determinación del mismo Amauta: antes y después del año 19. En la primera y bajo el seudónimo de Juan Croniqueur, desarrolló una actividad intelectual concorde con el medio, practicando el periodismo en Turf, Lulú, Mundo Limeño, La Prensa, El Tiempo, redactando crónicas parlamentarias y sociales, comentarios hípicos, en un clima de monotonía y laxitud, como prueban algunos títulos de sus artículos de entonces. Coautor de dos dramas, sonetista de carácter místico, cuentista fino y atildado, su gusto literario puede calificarse \footnotetext{
significa mezclado.

${ }^{1}$ En La Prensa, Lima $1^{\circ}$ de enero de 1914 . "Cabeceado" es un peruanismo que
} 
de 'modernista', con cierto aire decadente de fin de siglo. Afrancesado, alterna con la aristocracia de Santa Beatriz o del Palais Concert, para la que componía madrigales al pie de sus fotografías.

Los comentarios sobre artes plásticas que escribe en esta época son irrelevantes: justo al inicio del año 14 se entrampa en la polémica con Teófilo Castillo; en 1915 escribe cuatro artículos, dos dedicados a la pintura y dos a la escultura ${ }^{2}$; por sus contenidos llegamos a la certeza de que Mariátegui antes de viajar a Europa, no tenía, en materia de artes plásticas, un gusto definido, no conocía el lenguaje elemental artístico y tampoco los movimientos de vanguardia. Mariátegui se fogueó en el periodismo limeño, adquirió soltura expresiva, pero el medio pobre y huérfano de actividades culturales, frenó su disposición creativa. La segunda etapa comienza a partir del año 19 y dos son los acontecimiento que definen su personalidad y lo encaminan a la madurez: la asunción del socialismo y el viaje a Europa.

La inquieta inteligencia de Maríategui no se contenta con lo que el medio intelectual le ofrece. El, como muchos otros intelectuales de entonces, parte para otear otros horizontes, confrontarse y enriquecerse con nuevas experiencias. Mariátegui en Europa pone en acción su gran capacidad de asimilación, si se tiene en cuenta la corta estadía de 3 años y 7 meses tiempg en que modestamente, según él, "desposó una mujer y unas ideas". "Jorge Puccinelli Converso"

Desde Italia, donde estuvo la mayor parte del tiempo, Mariátegui envió a Lima numerosos artículos sobre literatura y arte, además de los dedicados a la política, que sumados a los que escribió a su llegada a Lima, pasan de la centena. Es la más contudente acción cultural y la más ambiciosa, emprendida por un sudamericano de la época. Sin embargo esta acción ha sido estudiada como si sólo tuviera que ver con las ideas, descarnadas de su contingencia social, siguiendo en este sentido una tradición idealista para estudiar las manifestaciones superestructurales. Pienso que se impone la metodología que el mismo Mariátegui vislumbraba cuando dice que los fenómenos literarios no deben examinarse en sí mismos, sino que hay que tomar en cuenta los demás fenómenos históricos, es decir

$$
2 \text { J.C. Mariátegui, Escritos juveniles. La Edad de piedra (3), p. } 295 .
$$


sociales y económicos. ${ }^{3}$ La obra de arte no es tal si de la considera sola y aislada; la literatura y en este caso la crítica de arte, no tienen sentido si no se integran a sus reales instancias, es decir, la producción, la distribución y el consumo. Las preguntas quién produce, por intermedio de quién y para qué tipo de consumidores, aclaran el complejo sistema de producción intelectual.

En la nutrida bibliografía existente sobre el $\mathrm{Amauta}^{4}$, Antonio Melis ha sido el primero en plantear el asunto de la producción en relación a Mariátegui y es acertado su juicio cuando dice que "en contacto con la experiencia europea, Mariátegui advierte que es imposible analizar un producto artístico prescindiendo de la noción de mercado. ${ }^{25} \mathrm{Y}$ en efecto, son claros los indicios de este tipo de interpretación en artículos como 'Populismo literario y estabilización capitalista' o en 'Zolá y la nueva generación francesa'. ${ }^{6}$

Mariátegui es un productor o como él mismo quiso denominarse, un "trabajador intelectual" que apremiado por la necesidad de subsistir, escribe, hace crítica, practica un género que por sus características siempre atrajo el interés de la pequeña burguesía ilustrada (pbi). Escribe además sobre los aspectos de la vida cultural que más atraían a una sociedad aislada y semifeudal como la limeña: sobre política, literatura y corrientes artísticas de yanguardia internacionales. Mariátegui, gracias a sus dotes de escritor moderno se fue ganando un mercado y fue creando un tipo de publico para sus artículos que antes no existía. El inaugura entre nosotros la figura del periodismo-literato, diferente del 'reportero' o del 'corresponsal' que envía sus comentarios dentro del típico estilo neutral de las agencias. La mayoría de los artículos de Mariátegui son de carácter informativo, pero con una tesis y teñidos con la pasión de la ideas que profesaba. El producto, es decir la crítica, se ve de alguna manera afectado por el modo físico de producir, el ritmo apremiente de la aventura editorial. En este sentido

${ }^{3}$ J. C. Mariátegui, "Literaturas europeas de vanguardia". En: Variedades, Lima, 28 de noviembre de 1925. Obras Completas, vol. 6, p. 114.

${ }_{5}^{4}$ Tírulo que se da al maestro en el Imperio Incaico.

5 Antonio Melis. "La lucha en el frente cultural". En: Mariátegui en Italia, Bruno Podestá, editor. Biblioteca Amauta, Lima 1981.

${ }^{6}$ Obras Completas, vol. 6, pp. 32 y 153 , respectivamente. 
los artículos de Mariátegui son eficientemente cortos, un promedio de dos y media a tres páginas, composiciones que pueden leerse rápidamene, de carácter sintético, cosa que el mismo Amauta destacó en varias oportunidades. ${ }^{7}$ El estilo cortante, de frases escuetas, tiene que ver con su "método para explicar y traducir nuestro tiempo", su prisa y su movilidad, "un método un poco periodístico y un poco cinematográfico". ${ }^{8}$ El carácter mismo del género 'crítica', testimonio de circunstancias, nada definitivo, marcó la producción de Mariátegui de manera inconfundible.

En Europa, Mariátegui se ve literalmente bombardeado por la información cultural que le llega a través de diarios y revistas y que procesará luego en Lima, en los años de su más intensa producción. Hay datos que le vienen de su directa experiencia, por ejemplo, entrevistas, visita a exposiciones, espectáculos, lecturas de textos originales que lo impactan vivamente. Otros le llegan indirectamente a través de comentarios de revistas que el Amauta interpreta de acuerdo a sus conocimientos y su sensibilidad.

No es mi intención examinar la estructura de la prosa de Mariátegui, pero sí de relievar algo que, después de todo, es fácil de percibir: el empleo en la mayoría de sus artículos, de un esquema binario de comparaciones que enfrenta personajes o situaciones para mejor examinarlos. Por ejemplo:iRema frentec 3 Milán, Vallejo frente a Melgar, Rilke contrapuesto a Essenin, como Bourdelle a Rodin. Hay sobradas evidencias de este sistema de oposiciones donde el paso de un argumento a otro contrario es contundente y seguro. Pero Mariátegui también recurre, desde sus escritos juveniles, al uso de las tríadas de adjetivos calificativos, ya destacado por Chang-Rodríguez. ${ }^{9}$ La reiteración de este procedimiento, por momentos cansadora, también caracteriza sus artículos de madurez y puede interpretarse como la intención de modelar escrupulosamente sus frases, o también, como un signo de insatisfacción. Sin embargo, cuando quiere llegar a alguna

${ }_{8}^{7}$ Carta a Ricardo Vegas García, Obras Completas, vol. 6, p. 183.

${ }^{8}$ Prólogo a La escena contemporánea, Primera edición, Lima 1925. Obras Completas, vol 1, p. 11.

${ }^{9}$ Eugenio Chang-Rodríguez. Poética e ideología en José Carlos Mariátegui, Edición Normas Legales, Trujillo, Perú, 1986, p. 61 (segunda edición). 
conclusión que no deje lugar a dudas, utiliza la dialéctica clara y rotunda del enfrentamiento binario. ${ }^{10}$ Insinuar, como se ha hecho, que el uso reiterativo que hace Mariátegui del número tres tiene relación con la Divina Trinidad, es una especulación esotérica, sin ningún fundamento ${ }^{11}$.

¿Cuál es la finalidad de la crítica de Mariátegui? Existen, desde luego, motivaciones altruistas: Mariátegui es un ideólogo, con sensibilidad social y mentalidad abierta hacia la cultura internacional, con una clara convicción del papel que debe cumplir el intelectual en la renovación de la sociedad. Pero sin merma de lo anterior, Mariátegui buscó y formó un nuevo mercado para el tipo de trabajo que realizaba. $\mathrm{Al}$ pasar a poseer los medios de producción -recuérdese que fundó la revista Amauta en 1926- Mariátegui asuguró a sus ideas un nuevo mercado editorial. La creación de la revista y la editora Minerva constituyen el programa cultural más exitoso en el Perú de la década del 20, promovido por un 'trabajador intelectual' como Mariátegui.

\section{Los temas}

La diversidad de temâs que aborda Mariátegui dice claramente de su concepción cultural, abierta, plural, donde los fenómenos están interconectados y noppueden tserctratados aistadamente: arte, política, economía, técnica, interactúan en eli complejomundo social. Desde luego que uno de los primeros esfuerzos por comprender los mecanismos de la sociedad europea fue entrar de lleno en la vida política, estudiar las tendencias, leer a sus clásicos, pero paralelamente incursionar en las manifestaciones culturales, que en la década del 20 atravesaban por un período de renovación y crítica. Aunque en buena parte de sus artículos se ocupa de asuntos políticos, el tema de la cultura no es menos importante: literatura, artes plásticas, teatro, cine, educación, se presentan estrechamente ligados a sus productores, los artistas, y al medio social en que éstos producen, estableciéndose una clara diferencia con la manera tradicional de tratar los fenómenos culturales, es decir aislada y descriptivamente.

10 "Mussolini y el fascismo" y "D'Annunzio y la política italiana". En: Obras Completas, vol. 1, pp. 15 a 18.

${ }^{11}$ Eugenio Chang-Rodriguez. Op. cit., p. 6. 
Le interesa fundamentalmente la interacción entre artista y sociedad, pero también el problema discutido entonces sobre realidad y ficción, decadencia y burguesía, el compromiso social del artista y las relaciones del arte y la política. Dentro de este conjunto, que hace posible la caracterización estética de Mariátegui y la visión de sus aportes a la crítica de arte en el Perú, merece especial mención el tema de las vanguardias, que trataremos de resumir en las líneas que siguen.

\section{Las vanguardias}

J.C. Mariátegui utiliza genéricamente el término vanguardia para designar un movimiento renovador y revolucionario en el marco de la cultura centroeuropea. Su defensa de los movimientos vanguardistas es entusiasta, porque los entiende como una búsqueda inteligente y noble y sus protagonistas "extrañamente poseídos por el afán de descubrir una verdad nueva, recorren austeramente penosos y miserables caminos." ${ }^{12}$ Más adelante, pasado el entusiasmo del primer momento, y con la calmada perspectiva de un análisis a distancia, su concepto de vanguardia se particulariza y en el contexto de sus escritos del año 24, la vanguardia está asociada al arte de imitación, al exotismo, al eclecticismo y sus productores son cada vez más "versátiles y tornadizos". "En suma, -dice- las escuelas son múltiples; la inquietud de los artistas es infinita; la moda es fugaz; la búsqueda es insaciable. ¿Hay que ver en todo esto, como Spengler, más que ninguna orra" cosa, un síntoma del tramonto de la civilización occidental?". ${ }^{13}$ Hay que ver en esta pregunta suspendida una respuesta implícita: Mariátegui cree ciertamente que las vanguardias reflejan la situación decadente de la sociedad europea "cuya existencia no tiene forma interior", según ha dicho Spengler, y anota acertadamente, la separación cada vez más notoria entre obra y público. Las obras de vanguardia "desconciertan y contrarían al vulgo" y "el gusto común rechaza hoy a la Venus de Archipenko". ${ }^{14}$ Pero, en esta sociedad cada vez más fragmentada, dispersa e impersonal, el arte de vanguardia significa una voluntad de afirmación humanista y también de la individualidad creadora, donde

${ }^{12}$ Obras Completas, vol. 6, p. 84.

${ }^{13}$ Op. cit., p. 61.

${ }^{14}$ Op. cit., p. 63. 
sólo la heterodoxia es rescatable: "El arte es sustancial y eternamente heterodoxo...". ${ }^{15}$ Conforme va estudiando los movimientos vanguardistas, Mariátegui tiene más base para caracterizarlos; el arte de vanguardia medra y hasta "entra de puntillas al museo", pero hay mucho de snobismo y ostentación en sus planteamientos y el público se ríe de él. Sin embargo Mariátegui destaca algunos aportes ya visibles en los movimientos de vanguardia, como el asumir creativamente la velocidad (Futurismo), el juego y el deporte (Dadaísmo) o el culto a la forma (Constructivismo). En relación a esto último Mariátegui escribe: "Dentro del concepto novísimo, la forma es todo: es forma y contenido al mismo tiempo. La forma resulta el único fin del arte."16 Declaración que lo hace aparecer como un formalista convencido y que sin embargo no es más que un entusiasmo pasajero. Más tarde, cuando adhiere al indigenismo de Sabogal, estará muy lejos de ser formalista; en todo caso, con su teoría del "valor-signo", no oculta las cualidades simbólicas de la imagen. Mariátegui, de regreso al Perú, deja de lado el entusiasmo inicial que le causaron las vanguardias y aporta críticas certeras, como cuando reconoce el carácter imperialista, conquistador y expansivo de las escuelas artísticas modernas ${ }^{17}$, cuando disiente con Breton a raíz de la publicación del Segundo Manifiesto Surrealista ${ }^{18}$, o cuando reconoce la conversión de Marinetti al fascismo. ${ }^{19}$ Mariátegui terminará creyendo quẹ lasi variguardias soncturiesintoma y un producto legítimos, peculiarẹs ygespantảneds delureascivilización que se disuelve y que decae." Esta frase pesimista hace pensar que los ejemplos europeos no tenían ya la importancia que les dio en un primer momento y que sólo queda buscar al interior de esa región incierta y oscura, como el alma de un adolescente, que es Latinoamérica. Desde luego que la perspectiva es otra cuando Mariátegui se enfrenta a las nuevas propuestas de los artistas peruanos. El indigenismo, tomado como valor-signo, representa para el Amauta, en ese momento, una salida esperanzada por donde pueda caminar segura el "alma matinal".

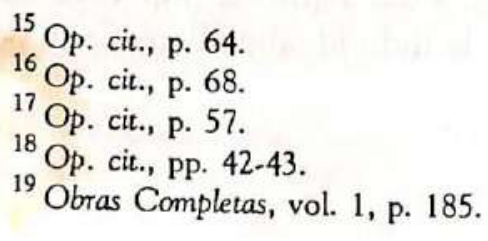

